\title{
Theme for 2015: Integration
}

\author{
Peter G. M. de Jong ${ }^{1}$
}

Published online: 30 October 2015

(C) International Association of Medical Science Educators 2015

Beginning this year, Medical Science Educator will be featuring journal sections on a specific topic. The content for the thematic sections has been solicited by a special call for manuscripts, and for 2015, the accepted articles will be published in issues 25(3) and 25(4). The theme that has been selected for 2015 is integration. The concept of integration is important in medical education in general. Think of integration of basic science knowledge in clinical teaching, integration of clinical cases in the basic science curriculum, and integration of several disciplines or pedagogies into one teaching unit. Medical Science Educator wants to explore the effects and outcomes of integration by learning what institutions are doing in this area.

The journal received almost 30 manuscripts for this section, and the first three articles were published in the previous issue. In this issue, the next 11 articles are included: 1 innovation, 3 short communications, 3 research pieces, 2 monographs, and 2 commentaries. Several of these articles address the integration of basic and clinical sciences in the curriculum, a topic that has proven to be of importance for many in medical education. I hope you will enjoy these 11 articles on the topic of integration.

There are still some submissions from this special call on integration under revision. As soon as these are accepted for publication, we will publish them in one of the regular issues of 2016.

Peter G.M. de Jong, PhD.

Editor-in-Chief

Peter G. M. de Jong

P.G.M.de_Jong@lumc.nl

1 Leiden University Medical Center, Leiden, The Netherlands 